\title{
DIMENSÕES DE ATUAÇÃO EM CONTEXTO INCLUSIVO: A AULA DE ARTE MEDIADA PELO SEGUNDO PROFESSOR
}

Regina Finck Schambeck ${ }^{\mathrm{i}}$

Katheryne Vieira da Luz ${ }^{\text {ii }}$

\begin{abstract}
Resumo: A presente pesquisa tem por objetivo investigar as conexões entre professoras de arte, segundo professor e a Educação Especial, de modo a compreender o ponto de vista das profissionais sobre as dificuldades e adaptações curriculares necessárias para inclusão de alunos com deficiência nas escolas regulares. As profissionais participantes desta pesquisa pertencem à rede municipal de Santo Amaro da Imperatriz do estado de Santa Catarina. A questão de pesquisa buscou identificar qual era a opinião das professoras de Arte e das professoras que atuam como segundo professor sobre a prática escolar envolvendo a Inclusão. A partir da abordagem da pesquisa qualitativa, mediante a sistematização de observações, da realização de entrevista semiestruturada e da aplicação de questionários, foi possível evidenciar as atividades desenvolvidas, as funções das segundas professoras no contexto escolar e, principalmente, ações de parceria entre as duas categorias de profissionais envolvidas no processo de inclusão de alunos com deficiência na rede municipal de ensino investigada. A análise de dados trouxe em evidência a formação inicial e/ou continuada, tangenciando aspectos que precisariam melhorar em busca de um 'ideal' para que a inclusão fosse efetivada no contexto analisado.
\end{abstract}

Palavras Chave: Inclusão. Aula de Arte. Segundo professor.

\section{PRATICE DIMENSIONS OF INCLUSIVE CONTEXT: THE ART CLASS MEDIATED BY THE SECOND TEACHER}

\begin{abstract}
The present research aims to investigate the connections between art teachers, second teacher and Special Education, in order to understand the professionals' point of view on the difficulties and curricular adaptations necessary to include students with disabilities in regular schools. The professionals that participated in this research belong to the municipal network of Santo Amaro da Imperatriz in the state of Santa Catarina. The research question sought to identify the opinion of the art teachers and the teachers who act as second teacher about the school practice involving Inclusion. Based on the qualitative research approach, through the systematization of observations, the semi-structured interview and the application of questionnaires, it was possible to highlight the activities developed, the functions of the second teachers in the school context and, mainly, partnership actions between the two professional categories involved in the process of inclusion of students with disabilities in the municipal education network investigated. The analysis of data brought in evidence the initial and / or continuous formation, tangentiating aspects that would need to improve in search of an 'ideal' so that the inclusion was carried out in the analyzed context.
\end{abstract}

Keywords: Inclusion. Art Class. Second teacher. 


\section{Introdução}

Este texto é fruto de pesquisa cuja temática abordou a adaptação de materiais pedagógicos para o professor de Artes em parceria com a Educação Especial, identificando como estes professores atuam em salas em contexto de inclusão em uma rede municipal de educação. A pesquisa foi realizada no município de Santo Amaro da Imperatriz, cidade de aproximadamente 22.000 habitantes $^{\mathrm{iii}}$, localizada na grande Florianópolis (SC). No ano de 2016, a rede municipal de educação do município possuía 13 unidades escolares, em cujas salas estudavam 38 alunos com necessidades educacionais especiais (NEE) matriculados nas classes comuns do ensino regular. A Secretaria Municipal de Educação segue a política de Educação Especial do estado de Santa Catarina e com base nesse documento, o município criou a Normativa $\mathrm{n}^{\circ}$ 01, de 03 de Novembro de 2008, que dispõe sobre o procedimento de contratação do segundo professor para turmas que tenham matricula de alunos com deficiência (SANTO AMARO DA IMPERATRIZ, 2008). Esse documento é responsável por orientar o atendimento dos alunos e a organização do atendimento educacional especializado no município (AEE). O setor de AEE do município não possui uma sala específica para o atendimento de alunos com deficiências em funcionamento e, portanto, cabe ao Serviço de Atendimento Educacional Especializado - SAEDE que funciona na sede da Associação de Pais e Amigos dos Excepcionais - APAE, a responsabilidade por atender a demanda desses alunos. A APAE também presta assessoria mensal ao SAEDE e promove cursos de capacitação para os profissionais da área.

O foco deste texto está nas conexões entre o professor de Arte e o AEE, através da atuação do segundo professor, a partir das práticas pedagógicas com alunos com deficiência em sala inclusiva no município. Assim, no trabalho, procura-se identificar as adaptações curriculares necessárias para a inclusão no ensino de Arte, bem como a atuação do segundo professor em sala de aula, fazendo-se menção aos marcos legais sobre os quais a implementação da inclusão nas escolas regulares daquele município foram implementadas. O segundo professor é o profissional que tem por função apoiar e correger a classe com o professor titular ou regente. Este profissional contribui, em função de seu conhecimento específico na área da Educação Especial, no desenvolvimento das atividades pedagógicas. Justifica-se, portanto, a importância desta pesquisa uma vez que ela pode dar um panorama sobre a inclusão em sala de aula, contribuindo para que os professores possam compreender como funciona a educação especial, o AEE, e as adaptações curriculares para a inclusão a partir das aulas de Arte.

Os dados foram coletados a partir da abordagem qualitativa, mediante o estudo de caso e foram organizados levando-se em consideração a estrutura da rede municipal de educação, suas 
características gerais, número de escolas e de professores de Arte, a presença ou não do profissional intitulado de 'segundo professor', a organização estrutural e pedagógica do setor de AEE nas escolas municipais, sua coordenação e supervisão, identificando as ações e o vínculo com a APAE. Para tanto uma entrevista foi realizada com a coordenação pedagógica da rede municipal e aplicados questionários semiestruturados para as professoras de Arte e demais profissionais que trabalham em parceria com o AEE. As questões que nortearam a elaboração do roteiro para o questionário foram organizadas de modo a abranger três categorias: formação; suporte pedagógico e a ação pedagógica com alunos com deficiência.

\section{Educação Inclusiva}

A educação inclusiva é um processo que aumenta a participação de todos os estudantes no ensino regular. Visa tratar todos os alunos com igualdade, levando em consideração as suas especificidades, “[...] a educação inclusiva dá voz a todos que foram historicamente calados, excluídos e considerados incapazes. [...] Extinguir o preconceito, compreender e respeitar as diferenças estão entre os principais objetivos de uma perspectiva de educação inclusiva." (BRASIL, 2008).

Segundo Morais (2007) a grande questão que perpassa a inclusão escolar está relacionada com a instrumentalização das escolas, em especial, a capacitação dos profissionais para receber o aluno com deficiência:

[...] a questão não é incluir, mas como incluir. Neste sentido, mudanças na forma de incluir serão benéficas para todos os alunos. Faz-se necessária uma política educacional que instrumentalize as escolas, capacite os profissionais que lidam com alunos que apresentam NEE e ainda, promova a participação dos pais no processo de inclusão. (MORAES, 2007, p.37).

Neste sentido, conforme nos aponta a autora, os professores deveriam receber orientação para oferecer este atendimento diferenciado nos processos de aprendizagem. Infelizmente, isto nem sempre é possível, devido à falta de incentivos e investimentos na correta preparação dos professores, sem falar na falta de material didático, apoio técnico e financeiro.

Gräff e Medeiros (2016) chamam a atenção para além da necessidade de formação dos profissionais que atuam no contexto inclusivo, a importância de um trabalho colaborativo entre políticas públicas e escolas na formação dos profissionais, sobretudo, do estabelecimento de espaços nas unidades para se discutir e criar estratégias pedagógicas para apoiar a inclusão, reforçando o que Moraes já destacava em seu texto de 2007. 
De acordo com o texto da Política Nacional de Educação Especial na Perspectiva da Educação Inclusiva (BRASIL, 2008) não há menção para adaptações curriculares, mas o texto admite que podem ser lançadas estratégias de atuação docente, decisões essas que oportunizem "os apoios necessários para sua participação e aprendizagem" (p.10) e/ou ainda "o professor deve criar estratégias considerando que alguns estudantes podem demandar ampliação do tempo para a realização dos trabalhos" (p.13). Nesta perspectiva, o processo de ensino e aprendizagem pressupõe atender à diversificação de necessidades dos alunos na escola.

Acredita-se que são as adaptações curriculares que possibilitam melhorias frente às dificuldades dos alunos. De acordo com Carvalho (2006) para se trabalhar na perspectiva da inclusão de pessoas com deficiências não se faz necessário um novo currículo, mas, sim, um currículo mais dinâmico, no qual fossem possíveis ajustes e ampliação para que de fato se atendam a todos os estudantes. O currículo para uma escola inclusiva, entretanto, não se resume apenas às adaptações feitas para acomodar os alunos com deficiências ou demais necessidades especiais. A escola inclusiva demanda uma nova forma de concepção curricular, que tem que dar conta da diversidade do seu alunado. A Declaração de Salamanca, documento elaborado pela UNESCO (1994, s/n), já destacava em seu texto a necessidade de a escola inclusiva adaptar processos de aprendizagem já que esta "reconhece e satisfaz as necessidades diversas dos seus alunos, adaptando-se aos vários estilos e ritmos de aprendizagem, de modo a garantir um bom nível de educação para todos [...]”. Não obstante, como indica Carbonell (2016) vozes críticas são ouvidas, pois a declaração ficou no meio do caminho, ou seja não deixou explícitas as reformas e as medidas necessárias para que a escola se faça inclusiva.

\section{Educação Especial}

De acordo com a Política de Educação Especial de Santa Catarina (2006), a Educação Especial é um processo interdisciplinar que promove o ensino e a reabilitação dos alunos com deficiência, condutas típicas e altas habilidades, usando para isto recursos pedagógicos e tecnológicos específicos. Este âmbito educacional passa por todos os níveis e modalidades do ensino e se apoia, complementa e suplementa a aprendizagem dos alunos.

[...] a todas as pessoas na faixa etária de zero a 14 anos deverá ser assegurado acesso, mediante a garantia de matrícula e de frequência, às escolas de Educação Infantil e do Ensino Fundamental e, como medida complementar, o poder público, através do sistema de ensino, disponibilizará um conjunto de recursos educacionais e serviços de educação especial que possibilitem a permanência, com qualidade, dos educandos com deficiência, condutas típicas e altas habilidades nas escolas da rede regular, garantindo- 
lhes o prosseguimento aos níveis mais elevados de ensino (SANTA CATARINA, 2006, $\mathrm{s} / \mathrm{n})$.

Mas como nos esclarece Moraes (2007) nem sempre tratar os estudantes com deficiência de maneira igualitária aos demais significa promover igualdade.

[...] incluir não é simplesmente inserir o aluno com necessidades educacionais especiais no ensino regular, antes de tudo é preciso que a escola se prepare para recebê-lo. E, para que as diferenças sejam respeitadas e se aprenda a viver na diversidade, é necessária uma nova concepção de escola, de aluno, de ensinar e de aprender (MORAES, 2007, p. 46).

Para a autora, garantir aos estudantes com deficiências o direito à inclusão é garantir o direito básico à igualdade, livre arbítrio e democracia. Assim, para que a inclusão ocorra de modo efetivo nas unidades escolares, é preciso que haja educação especializada nas escolas. As Diretrizes Nacionais para a Educação Especial na Educação Básica estabelecem:

Tornar realidade a educação inclusiva, por sua vez, não se efetuará por decreto, sem que se avaliem as reais condições que possibilitem a inclusão planejada, gradativa e contínua de alunos com necessidades especiais nos sistemas de ensino. Deve ser gradativa, por ser necessário que tanto a educação especial como o ensino regular possam ir se adequando à nova realidade educacional, construindo políticas, práticas institucionais e pedagógicas que garantam o incremento da qualidade do ensino, que envolve alunos com ou sem necessidades educacionais especiais (BRASIL, 2001, p.13).

Conforme previsto nas diretrizes lançadas em 2001, o desenvolvimento dos alunos com deficiências depende das relações com o meio e a troca de experiências em diferentes espaços e culturas, ou seja, a educação especial depende da equipe responsável por ela. Se o AEE ou o professor de classe não auxiliar o aluno na sua educação e cuidados talvez este seja mais excluído do que incluído, contrariando a proposta das diretrizes.

Oliveira (2012), levando em consideração o sistema vigente de educação, relata que ao mesmo tempo em que se garantem diversos direitos sociais, o sistema de organização social existente não considera de forma igualitária, a aquisição de informações, a capacidade de produção, reprodução e consumo, considerados como requisitos mais importantes para se inserir na sociedade. Acredita-se que é na escola que os alunos se motivam a estabelecer relações de trocas e é nela que todas as crianças constroem esse espaço natural de interação e que mais tarde se transfere para o convívio social.

De acordo com a Política de Educação Especial do Estado de Santa Catarina (2006, s/n), os serviços de Educação Especial são "serviços diversificados, oferecidos pelo poder público de forma direta ou indireta através das instituições conveniadas com a Fundação Catarinense de 
Educação especial - FCEE para atender as necessidades educacionais especiais da pessoa com deficiência, condutas típicas e altas habilidades".

O AEE busca pela autonomia e independência da criança na escola e fora dela. E, principalmente, a complementação da sua formação e não mais a substituição do ensino regular por escolas especiais. O aprendizado é mais fácil e tem mais sentido quando se está em um ambiente que permite a sua interação e participação. De acordo com as Diretrizes Operacionais para o Atendimento Educacional Especializado na Educação Básica (BRASIL, 2009) promover esta interação ajuda a eliminar as barreiras para a total participação do aluno na vida escolar, considerando sempre suas necessidades específicas de aprendizagem.

A Resolução CNE/CEB No. 4/2009 que trata do AEE está organizada em 14 artigos e cada uma das seções define como as instituições de ensino na educação básica deverão organizar esse atendimento. De acordo com o Art. $5^{\circ}$ o AEE é realizado, prioritariamente, na sala de recursos multifuncionais da própria escola ou em outra escola de ensino regular, no turno inverso da escolarização, não sendo substitutivo às classes comuns, podendo ser realizado, também, em centro de AEE da rede pública ou de instituições comunitárias, confessionais ou filantrópicas sem fins lucrativos, conveniadas com a Secretaria de Educação ou órgão equivalente dos Estados, Distrito Federal ou dos Municípios.

Quanto à elaboração e a execução do plano de ensino do AEE, esse deve ser feito em conjunto entre a professora que atua na sala de recursos e os demais professores do ensino regular, podendo ter a participação da família dos alunos e serviços de saúde e assistência social.

Segundo Gräff e Medeiros (2016) a oferta do AEE é uma forma de assegurar a garantia para a inclusão e, para que haja a Educação Inclusiva é preciso que serviços específicos oferecidos pelo AEE sejam colocados em prática nas escolas. Para as autoras a investida neste serviço e no profissional que o exerce é o principal ponto de sustentação das políticas de inclusão e aí destaca a figura do segundo professor.

\section{Segundo professor}

De acordo com o Programa Pedagógico do Estado de Santa Catarina (2009, s/n). Nas séries iniciais do ensino fundamental, o segundo professor, deve ser, preferencialmente, habilitado em Educação Especial. Sua função é "correger a classe com o professor titular, contribuir, em função de seu conhecimento específico, com a proposição de procedimentos diferenciados para qualificar a prática pedagógica". Deve, ainda, junto com o professor titular, 
“acompanhar o processo de aprendizagem de todos os educandos, não definindo objetivos funcionais para uns e acadêmicos para outros".

Nas séries finais do ensino fundamental, o segundo professor de classe terá como função apoiar, em função de seu conhecimento específico, o professor regente no desenvolvimento das atividades pedagógicas. Os dois professores serão orientados, concomitantemente, pelos profissionais do SAEDE e/ou Serviço de Atendimento Especializado - SAESP. É previsto um segundo professor quando houver em turma alunos com diagnóstico de deficiência:

De acordo com o texto do Programa Pedagógico do Estado de Santa Catarina (2009), dependendo do quadro funcional do aluno, este será atendido por um professor especialista, acompanhante terapêutico ou técnico da área da saúde. Seriam, assim, atribuições do segundo professor:

$>$ Planejar e executar as atividades pedagógicas, em conjunto com o professor titular, quando estiver atuando nas séries iniciais do ensino fundamental;

$>$ Propor adaptações curriculares nas atividades pedagógicas;

$>$ Participar do conselho de classe;

$>$ Tomar conhecimento antecipado do planejamento do professor regente, quando o educando estiver matriculado nas séries finais do ensino fundamental;

$>$ Participar com o professor titular das orientações (assessorias) prestadas pelo SAEDE e/ou SAESP;

> Participar de estudos e pesquisas na sua área de atuação mediante projetos previamente aprovados pela SED e FCEE;

$>$ Sugerir ajudas técnicas que facilitem o processo de aprendizagem do aluno da educação especial;

$>$ Cumprir a carga horária de trabalho na escola, mesmo na eventual ausência do aluno;

> Participar de capacitações na área de educação.

$>$ O segundo professor não pode assumir ou ser designado para outra função na escola que não seja aquela para a qual foi contratado.

O documento observa, ainda, que o segundo professor não deve assumir integralmente o(s) aluno(s) da Educação Especial, sendo a escola "responsável por todos, nos diferentes contextos educacionais: recreio dirigido, troca de fraldas, alimentação, uso do banheiro, segurança etc" (SANTA CATARINA, 2009, p. 17).

Um grande problema que se enfrenta hoje nas escolas catarinenses como um todo é a falta de laudo específico da deficiência, emitido por instituição de saúde, mediante avaliação médica. O fato de não se ter o 'laudo' acaba por prejudicar o aluno, pois este não tem o direito de ter um segundo professor para auxiliá-lo. Contudo, a escola detém a obrigatoriedade de ao 
identificar situações neste sentido, cabe a ela avisar ao conselho tutelar, mediando a colaboração junto à família para que seja garantido este direito à criança com deficiência.

Recentemente no estado de Santa Catarina, foi promulgada a legislação que regulamenta a presença do segundo professor na sala de aula em todo o sistema estadual de educação. A Lei $\mathrm{n}^{\circ} 17.143$, de 15 de maio de 2017, tem como objetivo central a valorização da educação especial e a proteção de direitos aos estudantes com deficiência. A lei obriga a presença do segundo professor nas salas de aula que tiverem alunos com diagnóstico de deficiência.

Apesar do Programa Pedagógico do estado de Santa Catarina (2009), definir as atribuições de atuação nas unidades escolares e a contratação desse profissional havia um veto do Governador do Estado que, justificando os custos da medida, se ausentava da responsabilidade de garantir esse direito a milhares de estudantes que necessitam de acompanhamento de profissional especializado. Como direito aos professores, a lei garante equiparação salarial e formação continuada. Em contrapartida, os profissionais deverão se envolver nas atividades pedagógicas, participar dos conselhos e da comunidade escolar e propor adequações curriculares que facilitem a aprendizagem e, de fato, proporcionem inclusão do educando no ambiente escolar.

\section{Professor de Artes}

De acordo com os Parâmetros Curriculares Nacionais (BRASIL, 1997) a Arte tem um grande poder de expressão. A partir da visão, escuta e os demais sentidos a Arte pode servir como porta de entrada para uma compreensão mais significativa das questões sociais. $\mathrm{O}$ estudo das artes propicia a compreensão dos valores, modos de pensar e agir, de outras culturas, favorecendo a valorização da diversidade da imaginação humana.

A educação em arte propicia o desenvolvimento do pensamento artístico, que caracteriza um modo particular de dar sentido às experiências das pessoas: por meio dele, o aluno amplia a sensibilidade, a percepção, a reflexão e a imaginação. Aprender arte envolve, basicamente, fazer trabalhos artísticos, apreciar e refletir sobre eles. Envolve, também, conhecer, apreciar e refletir sobre as formas da natureza e sobre as produções artísticas individuais e coletivas de distintas culturas e épocas. (BRASIL, 1997, p.15).

Na linguagem artística não existe um modelo correto a se seguir, de modo que todo mundo pode fazer Arte e pode participar de uma aula de Arte. Por isso, acredita-se no importante 
papel desempenhado pela Arte nos processos inclusivos, principalmente no trabalho com pessoas com deficiência, pois ela amplia as possibilidades cognitivas, ajudando quem não consegue se expressar do jeito convencional. De acordo com Klausen (2013):

Ao envolver os alunos com a produção artística, a arte pode operar com as percepções, possibilitando o desenvolvimento de diversas potencialidades, tais como: a observação, a imaginação, e a compreensão tátil do mundo. Ao construir o conhecimento artístico com os alunos, o professor também possibilita as trocas entre os mesmos, promovendo a aproximação do colega semelhante, bem como do colega diferente, ao buscar as significações na construção de sentidos do mundo da natureza e da cultura e ao trabalhar a sensibilidade, evocando a empatia e a abertura ao outro. (KLAUSEN, 2013, p. 11).

Como informa a autora algumas disciplinas têm uma organização pedagógica que privilegia o "exato e o padronizado", dificultando a aprendizagem daqueles que não compartilham esses processos convencionais. Já a disciplina Arte, diferentemente das disciplinas da área das exatas, por exemplo, oferece uma grande vantagem, pois nela são valorizadas a criatividade, intuição e imaginação, pois seus conteúdos podem ser interpretados de várias maneiras:

As linguagens da arte tem um sentido especial para o aluno com deficiência, porque nelas se valoriza a imaginação, o pensamento intuitivo. Nessas matérias, a identificação do erro é mais fugidia; entrementes, na avaliação, é preciso considerar a produção de cada um à luz das possibilidades e capacidades que vem demonstrando (MENDES; SILVA; SCHAMBECK,2012, p. 14).

No entanto, apesar de tão valorizada pelo poder de inclusão que apresenta, a disciplina Arte enfrenta um dilema na educação básica. Esse dilema está relacionado com a formação inicial e continuada dos professores que nela atuam. De acordo com Reily (2010), pesquisadora no campo das artes visuais, o professor nem sempre está preparado para atender a esse público:

A heterogeneidade é algo que o professor de Artes Visuais gerencia como parte de seu métier cotidiano. Entretanto, a diversidade se acentuou nas escolas brasileiras a partir do paradigma da inclusão, que assegura espaço no ensino regular para alunos com deficiências. Estes alunos podem necessitar de recursos para o atendimento de suas necessidades específicas em linguagem, motricidade e acesso ao conhecimento. A maioria dos cursos de licenciatura em Arte ainda não forma o professor para atuar na inclusão e, diante da falta de publicações na área, este se encontra despreparado para atuar no contexto da diversidade (REILY, 2010. p. 84).

Conforme mencionado anteriormente, a revisão de literatura apontou para a baixa produção acadêmica que discute e/ou apresenta propostas de criação de materiais cujo tema esteja voltado para um contexto inclusivo de modo a desenvolver e congregar estudos que 
problematizem as questões relativas às propostas de inclusão na Educação e na Arte. Portanto, o que se percebe pela produção acadêmica neste campo de conhecimento, e como foi destacado por Reily, cabe ao professor pesquisar sobre o assunto, colher materiais didáticos com colegas que já trabalharam com alunos com deficiência, buscando a partir destas trocas, a criação de novos materiais que o auxiliem e facilitem a aprendizagem e integração do aluno com o meio.

De acordo com Mendes, Silva e Schambeck (2012) o professor de Arte deve procurar conhecer o aluno, qual o seu contexto, as especificidades sobre a limitação com a qual convive para poder buscar os recursos e ajudas técnicas necessárias para sua participação plena na sala de aula. Para as autoras o papel do professor da Arte é também o de ampliar a criatividade, ludicidade e possibilidades educativas da realidade da criança. Reily (2010), por outro lado destaca que o problema é que muitos destes professores se sentem incapazes e mal preparados para criar materiais pedagógicos para os alunos com deficiência, pois a maioria ainda está tentando compreender e buscando estabelecer algum tipo de comunicação com o seu aluno com deficiência.

O estudo realizado por Schambeck (2015), na Universidade do Estado de Santa Catarina (UDESC), comprova o que Reily já apontava em 2010, ou seja, não são todos os cursos de Licenciatura que têm disciplinas que tratam da formação do futuro professor voltada para a inclusão. Ver abaixo os dados levantados pela pesquisa:

\footnotetext{
Conforme levantamento realizado junto aos projetos políticos pedagógicos dos cursos de licenciatura da UDESC, a única disciplina presente em todos os projetos de curso é Libras. Esta determinação tem base na Lei 10.436/2002, que trata da inclusão de Libras como disciplina curricular, e regulamentada em 22 de dezembro de 2005, pelo Decreto $\mathrm{n}^{\circ}$ 5.626. Este decreto determina, no parágrafo único do Art. $9^{\circ}$, que "as instituições de ensino médio que oferecem cursos de formação para o magistério na modalidade normal e as instituições de educação superior devem incluir Libras como disciplina curricular". Dos 10 cursos de licenciatura desta instituição, três oferecem disciplinas obrigatórias que tratam da formação de professores para atuar no contexto de inclusão e um curso apresenta uma disciplina eletiva (SCHAMBECK, 2015, p. 3).
}

De acordo com a autora, apesar de todas as medidas legais e adaptações curriculares para promover a inclusão na educação e sociedade, ainda há poucos cursos que oferecem disciplinas e preparam o professor para contexto inclusivo nas escolas. Paralelo a pouca ênfase dadas na formação inicial, outro problema identificado na pesquisa é que nas redes de ensino, muitas vezes, falta o incentivo para os professores fazerem parte de projetos de formação continuada. Para Schambeck (2015) é necessário oferecer e incentivar os professores a fazer uma formação continuada, de maneira que possam repensar a sua prática de ensino e este seria o papel que as instituições de ensino superior não podem deixar de cumprir. 


\section{Metodologia}

Inicialmente, como primeira etapa, procedeu-se a revisão de literatura, mediante um levantamento e consulta de documentos e referências sobre o tema da pesquisa. Posteriormente, como segunda etapa da pesquisa de campo, realizou-se a entrevista com a Coordenação de Educação Especial da rede municipal de educação de Santo Amaro da Imperatriz. Na sequencia, tendo obtido a anuência para a realização da pesquisa procedeu-se a aplicação de questionários semiestruturados com professoras de Arte, e das mesma forma, com as profissionais que atuavam como segundo professor.

As participantes da pesquisa são profissionais que trabalham com alunos com deficiências e foram escolhidas, intencionalmente, para o entendimento da prática escolar em relação a teoria que já vinha sendo estudada pelas autoras. Este estudo não tem a intenção de ser comparativo, mas, sim, estudar as relações entre as profissionais envolvidas nos processos educativos em Arte.

O fenômeno a ser investigado é a parceria entre as professoras de Artes e o setor de Atendimento Educacional Especializado, de modo a evidenciar de que maneira essas professoras responsáveis pelo acompanhamento dos alunos com deficiência em sala de aula interagem com as profissionais que atuavam como segundo professor.

Desta forma, o estudo procura analisar as perspectivas de um grupo de indivíduos específico de profissionais, a respeito da inclusão de alunos com deficiência em sala de aula, trazendo em evidência suas percepções sobre a própria atuação em sala, dificuldades e apoio recebido do setor de AEE. Este estudo trata-se portanto, de uma pesquisa de estudo de caso, com características analíticas.

Figura 1 - Etapas da pesquisa 


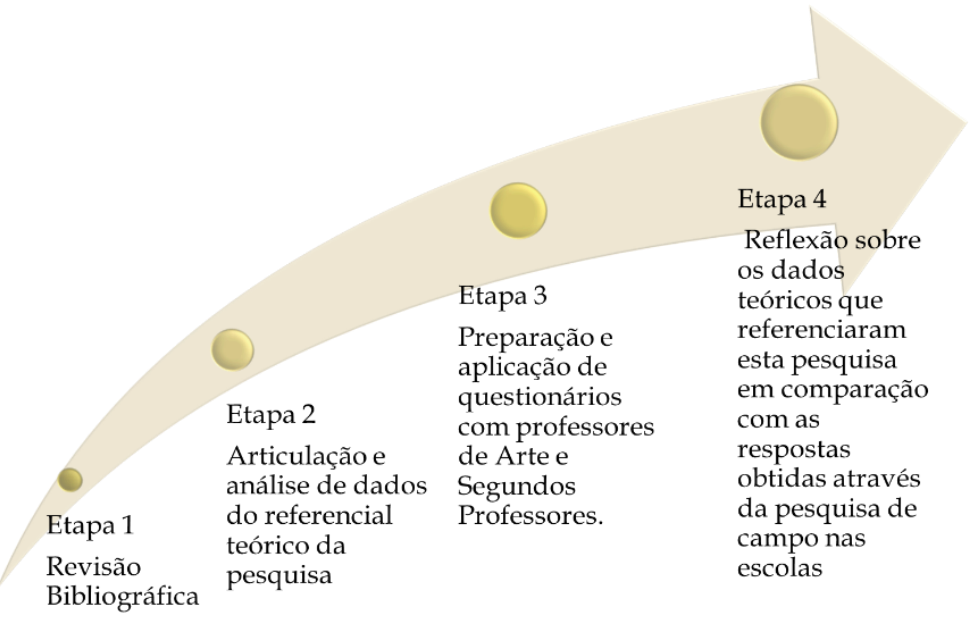

Fonte: Elaborado pelas autoras

Primeiramente, para situar o campo da pesquisa foi realizado um levantamento bibliográfico sobre a educação inclusiva e o Atendimento Educacional Especializado. Era preciso conhecer as normativas, leis e materiais de apoio que orientam a formação de professores para atuar em contexto de inclusão de alunos com deficiência, bem como os documentos que servem como suporte para as diretrizes de educação inclusiva do município de Santo Amaro da Imperatriz. Feito o levantamento bibliográfico pode-se, em etapa seguinte, fazer a classificação desse material. A terceira etapa envolveu a pesquisa de campo, com a preparação dos roteiros e coleta de dados. Fizeram parte desta etapa a realização da entrevista com a Coordenação de Educação Especial da rede municipal de educação do município e a elaboração e aplicação do questionário semiestruturado para as professoras de Arte, que lecionam a disciplina de Artes na Rede Municipal de Santo Amaro da Imperatriz e para as profissionais que atuam nas salas de aula como segundo professor, dando aporte aos alunos com necessidades educacionais especiais. A quarta etapa se constitui nas reflexões dos dados coletados buscando-se uma aproximação com a literatura.

Por essa se tratar de uma pesquisa que envolve pessoas, foram respeitados os critérios éticos estabelecidos pelo Comitê de Ética da UDESC para a realização de pesquisa, entre eles: a autorização para a realização da pesquisa junto a Coordenação de Educação especial da Rede Municipal de Educação de Santo Amaro da Imperatriz; Assinatura do Termo de Consentimento Livre e Esclarecido (TCLE) para a utilização dos dados coletados mediante a realização do questionário das sete professoras; Garantia do anonimato das professoras com a utilização de códigos numerados para os participantes. 


\section{Discussão e Análise dos Dados}

A análise dos dados constituiu-se na organização do material recolhido a partir do estabelecimento de quatro categorias: formação, suporte pedagógico, ação pedagógica com alunos com deficiência e parcerias com os segundos professores. Essas categorias foram articuladas com o referencial e a literatura apresentada na pesquisa.

Figura 2 - Dimensões da atuação do Professor de Arte

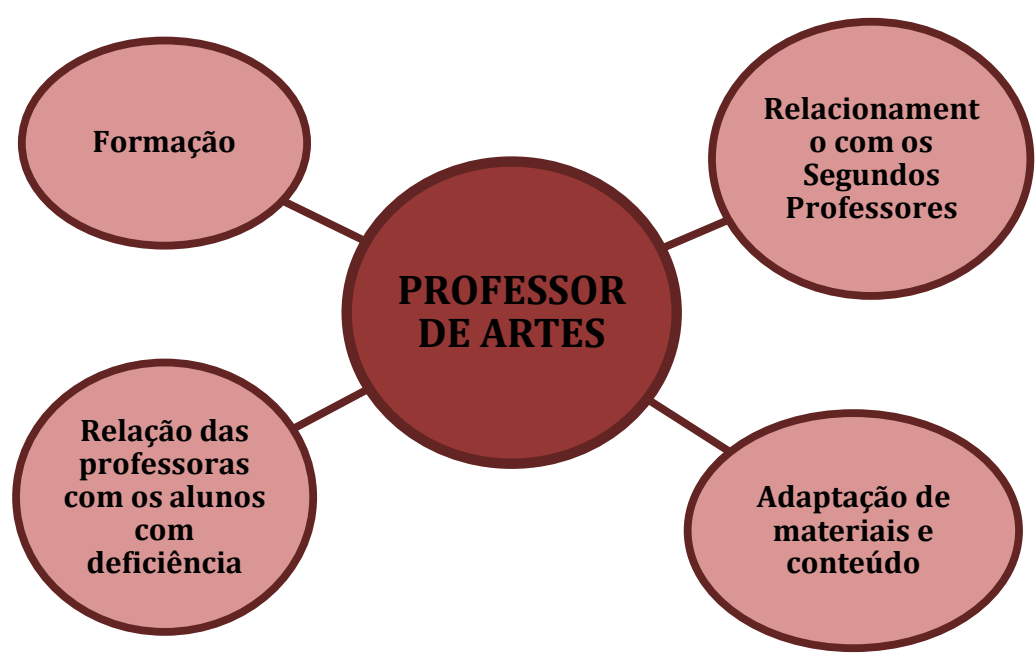

Fonte: elaborado pelas autoras

Quanto à formação das professoras de Arte pode-se concluir que, entre as três professoras participantes, nenhuma delas tem a formação específica em Artes Visuais. O levantamento indicou que duas delas têm formação em Educação Artística com habilitações em Cênicas e Música e a terceira professora não possui formação na área de Arte e, sim, em Pedagogia ${ }^{\text {iv }}$. Foi relatado pelas professoras que durante a graduação não houve nenhuma disciplina que desse aporte para a educação especial. Todas as três professoras tem pós-graduação, a PA1 é pósgraduada em Multidisciplinas, a PA2 é pós-graduada em Gestão Escolar e a PA3 é pós-graduada em Gestão e Metodologia de Ensino. Mesmo possuindo em suas turmas alunos com deficiências todas as professoras relataram não buscar nenhuma espécie de formação continuada na área de educação especial.

Tabela 1 - Professoras de Artes

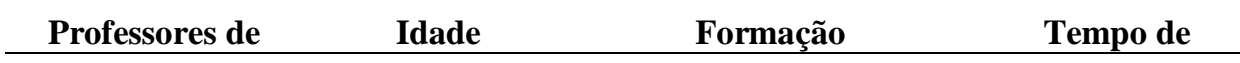




\begin{tabular}{|c|c|c|c|}
\hline Artes & & & Serviço \\
\hline Professora (PA1) & 56 anos & $\begin{array}{c}\text { Pedagogia com pós- } \\
\text { graduação em } \\
\text { Multidisciplinas }\end{array}$ & 35 anos \\
\hline Professora (PA2) & 42 anos & $\begin{array}{c}\text { Licenciatura em Artes } \\
\text { com habilitação em } \\
\text { Música. } \\
\text { Pós-graduação em } \\
\text { Gestão Escolar }\end{array}$ & 15 anos \\
\hline Professora (PA3) & 32 anos & $\begin{array}{l}\text { Educação Artística - } \\
\text { Artes Cênicas. Pós- } \\
\text { graduação em Gestão e } \\
\text { Metodologia de Ensino }\end{array}$ & 12 anos \\
\hline
\end{tabular}

Fonte: elaborada pelas autoras

Todas as três professoras de Arte são efetivas no município. Apesar de haver uma diferença discrepante entre o tempo de serviço da PA1 das demais, todas trabalham há bastante tempo na rede de ensino de Santo Amaro da Imperatriz.

A relação das professoras com os alunos com deficiências foi classificada da seguinte maneira:

PA1: Difícil.

PA2: Procuro fazer a interação de todos com as atividades aplicadas em sala de aula.

PA3: Não sei como lidar, pois uns necessitam de mediação frequente e às vezes não dá tempo.

Ao mencionar a capacidade dos alunos com deficiências acompanharem o conteúdo proposto, as professoras assim se manifestaram:

PA1: Muito difícil.

PA2: Muitas vezes incompreensível, não deve ser subestimado, pois é uma descoberta nova a cada dia.

PA3: Não vejo problema, pois uso da avaliação diferenciada e realizo atividades conforme considero necessário.

As professoras que manifestaram dificuldades em lidar com as deficiências corroboram com a opinião de muitos outros (ver trabalho de XXXX, 2009), ao se referir ao trabalho inclusivo em sala de aula. Ao analisar as respostas dadas pelas professoras percebe-se um desencontro nas afirmativas, pois enquanto algumas acham 'difícil e incompreensível', a outra adapta conteúdo e as suas avaliações, conforme a necessidade individual de cada aluno. Acredita-se que enquanto houver apenas reclamações, nada pode ser melhorado. É preciso agir e pensar em maneiras para atender esses alunos e ajudá-los a melhorar a capacidades de acompanhar o conteúdo. Isso implica em uma mudança da perspectiva dos docentes em relação Revista Interinstitucional Artes de Educar. Rio de Janeiro, V. 4, N.1- pág. 132 - 156 - (jan. - abr. de 2018): "Questões contemporâneas sobre a Educação Especial na Perspectiva da Educação Inclusiva" - 
às competências cognitivas e culturais, implica transformar os sistemas de ensino e aprendizagem e o modo de desenvolver o currículo (CARBONELL, 2016, p 108).

Dentre os conteúdos das aulas de Arte as profissionais identificaram dificuldades na apropriação de alguns conteúdos, dependendo das necessidades específicas de cada criança. Apesar de encontrar dificuldades, apenas a Professora de Arte PA3 procurou adaptar, na prática, o conteúdo de Arte proposto no seu planejamento anual. A professora menciona que busca ferramentas junto à segunda professora para tornar a adaptação de conteúdo viável. Para ela, a Segunda Professora possibilita o melhor aproveitamento das aulas de Arte por esses alunos.

As professoras de Arte PA3 e PA1 comentam sobre isso:

PA3: No planejamento sempre se coloca que adapta-se o conteúdo, conforme a necessidade, mas é ilusório dizer que adapta-se com a segunda professora.

PA1: O Segundo Professor não participa, está mais para cuidar do aluno.

Segundo a professora PA1, quando ela encontra dificuldade de incluir os alunos com deficiência, ela recorre geralmente a colegas de profissão e faz trabalhos individuais. A PA2 manifesta que procura não pensar nas dificuldades antes delas existirem. A professora de Arte PA3 indica que sempre busca por ajuda do Segundo Professor. As professoras, contudo, não aprofundam como fazem essa adaptação e como seriam os trabalhos individuais propostos aos alunos com deficiência.

Percebe-se que enquanto a professora PA1, formada em pedagogia, não busca por parcerias e nem adapta seus materiais, as outras professoras apresentam menos resistência e dificuldades em aceitar alunos com deficiência em suas aulas. Pressupõe-se que a formação em Pedagogia, em algum momento do curso inicial pode ter abordado, com mais ênfase, as dificuldades de aprendizagem e estratégias para adaptar conteúdos. Já nas falas das professoras PA2 E PA3, ambas com formação inicial em Educação Artística foi identificada a necessidade de adaptar materiais e estabelecer parcerias com as Segundas Professoras. Abaixo o depoimento da Professora PA1:

PA1: É muito difícil ter 45 minutos de aula e chegar a atender pessoalmente. Penso que apesar destes alunos terem direito a conviver e brincar com crianças ditas normais, eles em sala, muitas vezes, são apenas, mais uma dificuldade que o professor tem que enfrentar. Pois como falei, se você tem 35 alunos em sala e 1 tem deficiência grave, você tem de escolher entre atende-lo ou dar atenção aos outros 35. Neste caso, opto por falar igual e ensinar da mesma forma. Pois fica difícil planejar e trabalhar de forma diversificada. 
É unanimidade entre as professoras que participaram desta pesquisa a existência de um déficit na formação continuada. Perguntadas sobre o que poderia ser feito para um melhor apoio e suporte aos alunos com deficiência em sala de aula, as Professoras de Arte PA2 e PA3 classificaram como importante a realização de cursos de formação para todos os professores. Indicaram, também, a necessidade de se abordar nestes cursos a deficiência de forma ampla, contemplando de uma maneira geral, as características de aprendizagem deste público e formas de avaliação. Também foi sugerida a realização de um simpósio ou mesmo de palestras para que se conheça a realidade da educação especial, além de mais apoio das Instituições responsáveis por essa área.

É bom lembrar que a formação continuada não pode ser considerada apenas palestras ou simpósios onde as professoras apenas assistam a um orador explicar sobre as deficiências dos alunos. A formação continuada deve estimular o professor a refletir sobre a sua prática, conscientizando-os da importância de ser um professor mediador, que tem real interesse na aprendizagem dos alunos e não apenas um professor expositor com uma prática descontextualizada para o contexto inclusivo. De acordo com Moraes (2007):

\footnotetext{
Um trabalho de formação continuada precisa ir além da exposição de teorias, a fim de propor uma reflexão a partir da prática docente. Neste sentido, a proposta deve trabalhar com a formação de professores reflexivos, aqueles que diante das dificuldades descartam a ação rotineira (que é impulsiva, tradicional e autoritária) para optar por uma ação reflexiva, que é uma visão ampla do problema, não ficando, preso somente a uma forma de atuação (p 114).
}

Cada professora tem a sua maneira de trabalhar e a sua história de vida, com carreira rpofissional formada diferentemente. Pode-se pensar em várias questões para explicar a discrepância entre as respostas dadas, mas acredita-se que se o pensamento de inclusão fosse mais incentivado pela instituição escolar, todas elas poderiam ter uma maior conscientização sobre ações inclusivas, não esperando apenas por políticas públicas e/ou ação da coordenação de educação especial para realizar as modificações necessárias para atuar com alunos com deficiência. Acredita-se que se cada uma adaptasse o seu planejamento para abraçar todos os alunos já seria um bom começo para a inclusão acontecer na prática. 


\section{Segundo Professor}

Figura 3 - Dimensões da atuação do Segundo Professor

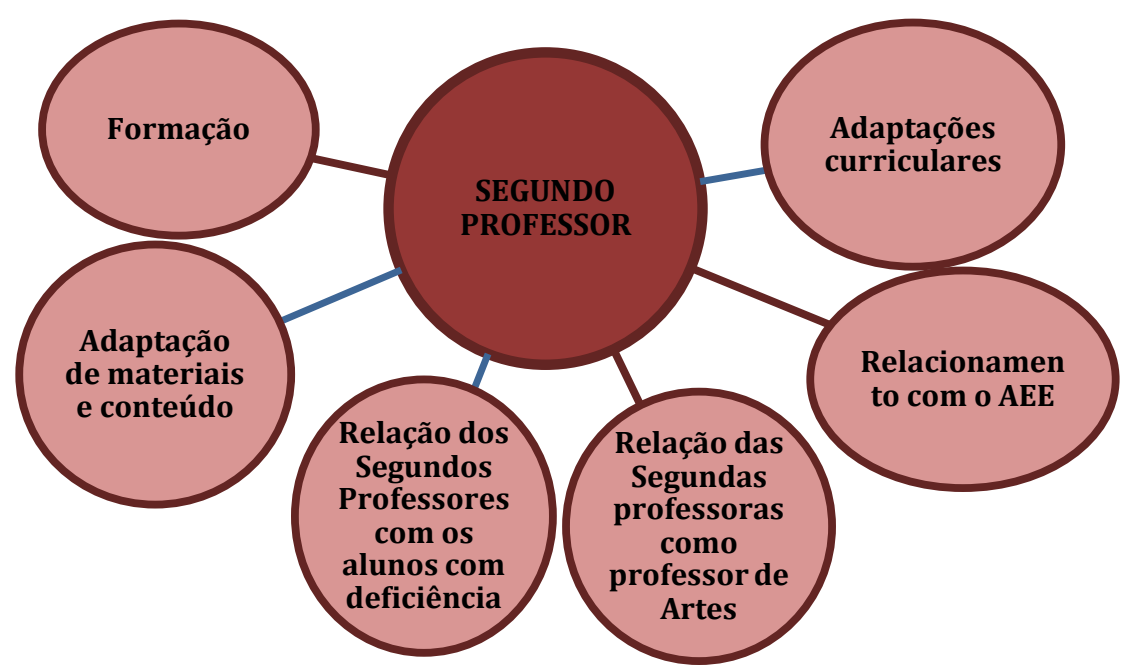

Fonte: elaborado pelas autoras

Todas as professoras que atuam como Segundo Professor são "admitidas em caráter temporário" (ACTs). Quando perguntadas sobre as deficiências dos alunos com os quais trabalham ou já trabalharam, foram mencionadas: Hiperatividade (três referências), seguida de Autismo e Síndrome de Down (duas referências cada). Quase todas as professoras são formadas em Pedagogia, apenas uma ainda não concluiu sua formação inicial. Não se observou nas respostas do grupo indicação de atendimento ao que determina o Programa Pedagógico do Estado de Santa Catarina (2009, s/n), ou seja, que nas séries iniciais do ensino fundamental, o Segundo Professor, deveria ser, preferencialmente, habilitado em Educação Especial. Pode-se perceber ainda que o perfil dessas profissionais é de mulheres, jovens e com pouco tempo de serviço no município, se comparadas às professoras de Arte.

Tabela 2 - Segundas professoras 


\begin{tabular}{|c|c|c|c|c|}
\hline $\begin{array}{c}\text { Segundas } \\
\text { Professoras }\end{array}$ & Idade & Formação & $\begin{array}{l}\text { Tempo de } \\
\text { Serviço }\end{array}$ & $\begin{array}{l}\text { Deficiências dos } \\
\text { alunos com os } \\
\text { quais trabalha ou } \\
\text { já trabalhou }\end{array}$ \\
\hline $\begin{array}{l}\text { Professora } \\
\quad \text { (SP1) }\end{array}$ & 28 anos & Pedagogia & 6 anos & $\begin{array}{c}\text { Hiperatividade, } \\
\text { Microcefalia e } \\
\text { deficiência mental } \\
\text { moderada }\end{array}$ \\
\hline $\begin{array}{l}\text { Professora } \\
\quad(\text { SP2) }\end{array}$ & 31 anos & $\begin{array}{c}\text { Pedagogia, } \\
\text { cursando } \\
\text { complementação e } \\
\text { pós-graduação em } \\
\text { Educação Especial. }\end{array}$ & 4 anos & $\begin{array}{c}\text { Autismo, Síndrome } \\
\text { de Down, Paralisia } \\
\text { Cerebral, Síndrome } \\
\text { do Alcoolismo } \\
\text { Fetal, } \\
\text { Hiperatividade e } \\
\text { Défice de Atenção }\end{array}$ \\
\hline Professora(SP3) & 40 anos & Pedagogia & $\begin{array}{c}1 \text { ano e } 10 \\
\text { meses }\end{array}$ & Autismo. \\
\hline $\begin{array}{l}\text { Professora } \\
\quad \text { (SP4) }\end{array}$ & 19 anos & $\begin{array}{l}\text { Cursando } \\
\text { Pedagogia }\end{array}$ & 2 meses & $\begin{array}{l}\text { Síndrome de Down, } \\
\text { Transtorno do } \\
\text { Déficit de Atenção } \\
\text { com Hiperatividade } \\
\text { e Bipolaridade. }\end{array}$ \\
\hline
\end{tabular}

Fonte: elaborada pelas autoras

As professoras que atuam na função de Segundo Professor afirmaram que o conhecimento teórico que tiveram sobre educação inclusiva na graduação nem sempre foi igual ao que encontram, efetivamente, na prática escolar. Especificamente pelo depoimento da professora SP1, que relata ter se deparado na realidade escolar, com situações que necessitaram de uma pesquisa mais profunda sobre educação inclusiva, do que a que tiveram durante a graduação. Da mesma maneira, SP2 também indica que a educação inclusiva poderia ter sido estudada e trabalhada com mais profundidade na graduação. Mesmo, assim, considera importante o conhecimento que teve para compreender um pouco mais sobre a educação inclusiva. O fala da professora SP3 elucida o que foi apresentado acima:

SP3: A prática é diferente da teoria, no entanto para compreender a prática você precisa do conhecimento teórico, e por isso a graduação foi muito importante, para compreender o que é a educação inclusiva, sua história ao longo de todos esses anos, como deve ser concebido nas escolas, qual o papel do professor, os aspectos legais que buscam garantir o direito das pessoas com deficiência, dos excluídos do meio social, educacional e até profissional. A formação acadêmica não te dá conhecimento especifico para cada deficiência ou síndrome, é trabalhando de forma superficial, que você vai aprofundar esse conhecimento com uma especialização ou conforme a realidade e necessidade de cada criança que você for trabalhar, através de pesquisas e troca de informações com a família ou com AEE e APAES. O que não é diferente no ensino regular, não existe uma única receita que atenda a todas as crianças na forma de ensinar e elas aprender, o professor precisa estar atento a cada criança, pois cada uma aprende de um jeito dentro do seu tempo. 
Já a segunda professora SP4, que ainda está cursando Pedagogia, contou que apesar do pouco tempo de atuação, percebeu que as dificuldades no trabalho que desenvolve na escola são maiores do que aquelas que esperava encontrar.

As professoras SP1, SP2 e SP3 acreditam que a inclusão dos alunos com deficiências está começando a acontecer nas escolas. Elas, afirmam que estão se envolvendo em questões sociais e pedagógicas para promover uma melhor aprendizagem dos alunos que acompanham. De acordo com a segunda professora:

SP3: [...] a própria sociedade está mudando a sua visão e comportamento perante o "diferente" e a Educação Especial ainda está em processo de adaptação.

Já a segunda professora SP4, pensa que a prática está muito longe da teoria, pois ela considera que:

SP4: A inclusão não é apenas estar dentro da sala de aulas, envolve o relacionamento com os demais, o aprendizado completo e, na maioria das vezes, no nosso dia a dia, isso não ocorre.

Sobre as dificuldades encontradas em trabalhar com os alunos com deficiência as segundas professoras relataram:

SP1:Compreender o que o aluno está pensando ou sentindo, pois muitas vezes eles não falam sobre.

SP2: As maiores dificuldades para mim são as estruturas escolares e os materiais de apoio. Já trabalhei com um cadeirante, mas a instituição não tinha nenhuma estrutura para receber aquela criança.

SP3: A maior dificuldade é você não receber informações suficientes sobre aquela criança, qual sua síndrome, ou deficiência, quais os recursos mais adequados para o bom desenvolvimento dela, até você fazer todo esse trabalho, muitas vezes já passaram meses. Também é muito falho o material didático adequado, acessibilidade nas escolas, ficam apenas nas APAES ou AEE.

SP4: A falta de assistência é a maior dificuldade, pois como estou iniciando precisava de maior auxilio, porque esta não é uma missão fácil.

A professora SP2 também levantou a questão de quantidade de alunos que cada segundo professor atende por sala:

SP2: Em relação à educação especial não concordo com alguns aspectos: cada professor pode ficar com até cinco crianças especiais em uma mesma turma, é muito difícil dar conta de todos e fazer com que todos tenham uma educação de qualidade. 
Apesar da Coordenação de Educação Especial do município afirmar que a APAE faz assessoria mensal e promove cursos de capacitação para os profissionais da Educação Especial, pode-se perceber pelas falas das professoras que a assessoria para a realização do trabalho não está acontecendo de maneira efetiva. As Segundas Professoras também afirmaram que não recebem muitos materiais de apoio para as suas aulas, mencionaram usar ou criar os seguintes materiais para dar suporte ao planejamento: "livros com ilustrações, jogos educativos, brincadeiras dirigidas, planilhas com alfabeto e números em EVA”. Assim, além e adaptar atividades e mudar alguns recursos quando necessário, este material, geralmente, é encontrado na biblioteca da escola e/ou comprado e produzido pelas mesmas de acordo com as suas necessidades.

De acordo com a Coordenação de Educação Especial da rede, o atendimento acontece todos os dias, com rotatividade de alunos, por volta de uma hora e meia de atendimento por aluno. O material didático utilizado para o atendimentos dos alunos se constitui de jogos pedagógicos, materiais que a fundação Catarinense de Educação Especial fornece, além da confecção pelas próprias professoras de alguns materiais adaptados.

Sobre a formação necessária para o profissional que trabalha com a Educação Especial, nas escolas municipais se dá prioridade para professores com formação em Educação Especial. De acordo com a Coordenação de Educação Especial quando não há profissionais com esta formação específica, são aceitos professores com formação em Pedagogia. O AEE é supervisionado pela coordenação da secretaria da educação do município e pela coordenação da APAE.

Pode se constatar pelas afirmativas das professoras que a relação com o AEE não está clara. De acordo com SP1, ela não sabe o que é o AEE. A SP2 conhece o AEE e afirma que os professores que atuam no setor se reúnem uma vez ao mês para trocar informações e ver os procedimentos a serem realizados. Já SP3 informa que, não ocorre um trabalho em conjunto entre o AEE, as escolas ou professores do ensino regular. A professora SP4 relata que em dois meses de trabalho, teve apenas um encontro com o AEE. Fica claro para as pesquisadoras que os dados coletados apresentam inconsistências e necessitariam ainda de um aprofundamento de modo a compreender como se dá a relação de cooperação entre as professoras e o AEE.

Finalizando, a partir das análises dos dados coletados as Segundas Professoras afirmaram gostar da sua profissão, apesar de mencionarem as dificuldades no desenvolvimento do trabalho nas unidades escolares, estão confiantes que possa haver melhorias na área em um breve futuro. Ao serem questionadas sobre quais seriam essas melhorias as professoras foram unânimes em manifestar o desejo por mais cursos de capacitação e o oferecimento de materiais pedagógicos Revista Interinstitucional Artes de Educar. Rio de Janeiro, V. 4, N.1- pág. 132 - 156 - (jan. - abr. de 2018): "Questões contemporâneas sobre a Educação Especial na Perspectiva da Educação Inclusiva" - 
adequados a cada deficiência. Acreditam ainda que uma maior assistência pedagógica e estruturas físicas em melhores condições de acessibilidade seriam fundamentais para tornar a escola inclusiva.

\section{Considerações Finais}

A revisão de literatura mostrou que a legislação brasileira está estruturada de modo a garantir os direitos das pessoas com deficiências no acesso e permanência à escolarização. Do mesmo modo, há um esforço por parte da Coordenação de Educação Especial do município de Santo Amaro da Imperatriz em implantar diretrizes para a inclusão escolar na rede de ensino. Porém, a pesquisa mostra que existem várias contradições e dificuldades no processo de construção de sistemas educacionais inclusivos, em especial o setor investigado.

Apesar do pouco material publicado sobre educação especial e educação inclusiva voltados para a disciplina de Arte, percebe-se, em contrapartida, um aumento no interesse e na busca por produções cujo foco sejam materiais e objetos pedagógicos. Eventos na área como palestras e simpósios sobre o tema tem acontecido com certa frequência, inclusive com propostas de capacitação na modalidade à distância (EAD). Acredita-se que essas iniciativas poderão contribuir para um melhor aporte teórico e ainda, como fonte de pesquisa para os profissionais da área de Arte e da área de Educação Especial que possam se interessar pelo tema.

No campo do ensino das Arte e da inclusão existe, atualmente, um grande debate em torno da relação entre essas duas áreas, como se dá essa aprendizagem e quais os materiais pedagógicos que poderiam ser adaptados para os alunos com deficiências. Contudo, a defasagem na formação dos professores neste campo, como apurado nesta pesquisa, pode dificultar o conhecimento e o acesso ao currículo e as adaptações necessárias para a inclusão dos alunos com deficiências. Defasagem, esta, que pode ser sanada com o oferecimento de disciplinas obrigatórias nos cursos de formação de professores da área de Arte para atuar no contexto de inclusão, além de mais propostas de integração entre o professor de Artes e o AEE, mediante a elaboração e execução de um plano de atendimento a partir de parcerias, identificando, organizando e produzindo serviços, recursos pedagógicos de acessibilidade como jogos e objetos adaptados.

Com base no levantamento de literatura realizado nesta pesquisa, em contrapartida com os dados apurados junto aos participantes, profissionais que trabalham com alunos com deficiência, pode-se concluir que a inclusão não está acontecendo de maneira efetiva na rede de ensino estudada. Conforme nos apontaram Reily (2010), Mendes, Fonseca da Silva e Schambeck 
(2012) inserir os alunos com deficiências em classes comuns do ensino regular não lhes assegura os mecanismos para promover a aprendizagem em Arte. Ao não adaptar o planejamento das aulas e os conteúdos para as crianças com deficiências, as professoras de Arte não garantem uma participação na aula de igual maneira aos demais alunos.

Acredita-se que para que haja inclusão seja necessário, entre outros aspectos, investir na qualificação dos educadores para uma atuação mediadora mais competente, ampliar e diversificar a equipe da Educação Especial do município e rever o modelo de intervenção direcionado para estes alunos junto à comunidade escolar. Além disso, é preciso melhorar o suporte e orientação às práticas pedagógicas de todos os educadores e não só dos Segundos Professores, tal como mencionado pelas participantes da pesquisa. Não se pode, portanto, responsabilizar apenas as profissionais nos processos de aprendizagem e inserção dos alunos com deficiência. Acredita-se que se houvessem mais projetos e/ou ações com base na interdisciplinaridade e do mesmo modo, planejamentos conjuntos, a inclusão aconteceria de maneira mais satisfatória. Afinal, segundo as participantes da pesquisa, é sempre bom compartilhar experiências e dúvidas sobre a educação especial com outros professores. Para as professoras investigadas seria interessante, também, que houvessem mais discussões coletivas sobre a prática escolar em contrapartida à teoria, buscando, na prática, soluções que poderiam ser pensadas para uma inclusão de todos os alunos. Este tipo de reflexão é muito importante, pois melhora o desenvolvimento profissional e pessoal do professor.

A relação entre as professores de Arte e as professoras que atuam como Segundo Professor na rede de ensino de Santo Amaro da Imperatriz, foco principal desta pesquisa, quase não acontece na prática. As participantes da pesquisa atribuem essa dificuldade à falta de incentivo por parte da Coordenação de Educação Especial do Município, já que nos últimos anos não foram promovidas capacitações, encontros e/ou até mesmo conversas sobre a Educação Especial entre todos os profissionais envolvidos na educação, o que as faz trabalhar isoladamente.

De acordo com os dados apurados nenhuma professora entrevistada procurou fazer curso de aperfeiçoamento na área da Educação Especial, mesmo tendo em suas salas alunos com deficiência. As práticas inclusivas relatadas pelas profissionais participantes da pesquisa no contexto do município de Santo Amaro da Imperatriz, ainda diferem muito do ideal preconizado pelas políticas públicas. Desse modo, a existência de leis, normas, ainda que bem intencionadas, não retratam o que se faz na realidade cotidiana daquelas escolas. Ainda com relação às conexões e eventuais parcerias com o Segundo Professor, apenas uma professora de Arte afirmou, eventualmente, fazer planejamento conjunto com a segunda professora. $\mathrm{O}$ que Revista Interinstitucional Artes de Educar. Rio de Janeiro, V. 4, N.1- pág. 132 - 156 - (jan. - abr. de 2018): "Questões contemporâneas sobre a Educação Especial na Perspectiva da Educação Inclusiva" - 
demonstra, pelo menos no universo pesquisado, que há um longo caminho a ser percorrido quando se trata dos processos de inclusão no ensino fundamental.

\section{Referências}

BRASIL. CNE. CEB. Resolução 2/2001. Diário Oficial da União, Brasília, 14 de setembro de 2001. Seção 1E, p. 39-40. Disponível em:

http://portal.mec.gov.br/cne/arquivos/pdf/CEB0201.pdf. Acesso em 31 de Maio de 2016, às $21 \mathrm{~h} 00 \mathrm{~min}$.

BRASIL. CNE. Resolução CNE/CP 1/2002. Diário Oficial da União, Brasília, 9 de abril de 2002. Seção 1, p. 31. Republicada por ter saído com incorreção do original no D.O.U. de 4 de março de 2002. Seção 1, p. 8. Disponível em:

http://portal.mec.gov.br/cne/arquivos/pdf/rcp01_02.pdf Acesso em 15 de Maio de 2016, às $14 \mathrm{~h} 50 \mathrm{~min}$.

BRASIL. MEC. CNE/CEB Resolução $n^{\circ}$ 4/2009. Diretrizes Operacionais para o Atendimento Educacional Especializado na Educação Básica, modalidade Educação Especial. Diário Oficial da União, Brasília, 5 de outubro de 2009, Seção 1, p. 17. Disponível em:

http://portal.mec.gov.br/dmdocuments/rceb004_09.pdf Acesso em 21 de Maio de 2016, às $16 \mathrm{~h} 15 \mathrm{~min}$.

BRASIL. MEC. CNE. Diretrizes Nacionais para a Educação Especial na Educação Básica. Brasília. 2001. Parecer n. ${ }^{\circ}:$ 17/2001. Disponível em:

http://portal.mec.gov.br/seesp/arquivos/pdf/parecer17.pdf Acesso em 31 de Maio de 2017, às $21 \mathrm{~h} 22 \mathrm{~min}$.

BRASIL. MEC. Política nacional de educação especial na perspectiva da educação inclusiva. Brasília, Janeiro de 2008. Disponível em:

http://portal.mec.gov.br/arquivos/pdf/politicaeducespecial.pdf Acesso em 24 de Junho de 2017, às $16 \mathrm{~h} 35 \mathrm{~min}$.

BRASIL. MEC/SEESP. Política Nacional de Educação Especial na Perspectiva da Educação Inclusiva. Documento elaborado pelo Grupo de Trabalho nomeado pela Portaria Ministerial $\mathrm{n}^{\circ}$ 555 , de 5 de junho de 2007, prorrogada pela Portaria $n^{\circ}$ 948, de 09 de outubro de 2007. Fonte: PORTAL EDUCAÇÃO. Disponível em:

http://peei.mec.gov.br/arquivos/politica_nacional_educacao_especial.pdf Acesso em 24 de Junho de 2017, às 16h45min.

BRASIL. MEC/SEF. Parâmetros Curriculares Nacionais - Artes - Brasília. 1997. 130p. Disponível em: http://portal.mec.gov.br/seb/arquivos/pdf/livro06.pdf Acesso em $04 \mathrm{de}$ Novembro de 2017, às 16h30min.

BRASIL. Lei no 10.845/2004. Programa de Complementação ao Atendimento Educacional Especializado às Pessoas Portadoras de Deficiência. Brasília, 5 de março de 2004. Disponível 
em: http://www.planalto.gov.br/ccivil_03/_ato2004-2006/2004/lei/110.845.htm Acesso em 15 de Maio de 2016, às 15h20min.

CARVALHO, Rosita Edler. Educação inclusiva: com os pingos nos "is". 4. ed. Porto Alegre: Ed. Meditação, 2006.

CARBONELL, Jaume. As pedagogia da inclusão e da cooperação. In: Pedagogias do século XXI: bases para a inovação educativa, $3^{\mathrm{a}}$ ed. Porto Alegre: Penso, 2016, p.101 - 126.

GRÄFF, Patrícia. MEDEIROS, Daniela. Inclusão escolar: Atendimento Educacional Especializado, expertise e normalização. Educação | Santa Maria | v. 41 | n. 1 | p. 197-208 | jan./abr. 2016. Disponível em: http://periodicos.ufsm.br/index.php/reveducacao/article/view/14450/pdf Acesso em 03 de Junho de 2016 , às $23 \mathrm{~h} 45 \mathrm{~min}$.

IBGE. Disponível em: http://cidades.ibge.gov.br/xtras/perfil.php?codmun=421570 Acesso em 27 de Maio de 2016, às 17h45min.

KLAUSEN, Adriana Paula Nunes Siqueira. O Ensino de Artes Visuais: Algumas possibilidades na aprendizagem da arte em alunos com Necessidades Educacionais Especiais. Porto Alegre. 2013. Trabalho de Conclusão em licenciatura em Artes Visuais - Curso de graduação em Artes Visuais do Instituto de Artes da UFRGS. Disponível em: https://www.lume.ufrgs.br/bitstream/handle/10183/67185/000873000.pdf?sequence=1 Acesso em 27 de Abril de 2016, às 22h50min.

MENDES, Geovana Mendonça Lunardi; SILVA, Maria Cristina da Rosa Fonseca, SCHAMBECK, Regina Finck. Objetos pedagógicos: uma experiência inclusiva em oficinas de artes. Araranguera, SP: Junqueira\&Marin, 2012.

MORAES, Marcela Cristina de. Mediação pedagógica, inserção escolar de alunos com deficiência mental e arte: um olhar sobre o projeto espaço criativo. 2007. Pg132. Disponível na biblioteca eletrônica SciELO. Disponível em:

http://www.scielo.br/pdf/ccedes/v30n80/v30n80a07.pdf Acesso em 22 de Fevereiro de 2016, às $23 \mathrm{~h} 00 \mathrm{~min}$.

OLIVEIRA, Andréa Duarte. Condições de formação continuada do programa Educação Inclusiva: direito à diversidade. 2012. P.103. Dissertação (Pós-graduação em Educação). Universidade Federal de Mato Grosso do Sul. Corumbá, MS. Disponível em: file:///C:/Users/Jo\%C3\%A3o/Downloads/ANDREADUARTEDEOLIVEIRA.pdf. Acesso em 03 de Junho de 2016, às 21h30min.

PORTAL EDUCAÇÃO. Adaptações curriculares na educação inclusiva. Artigo por Colunista Portal - Educação - quarta-feira, 24 de abril de 2013. Disponível em: http://www.portaleducacao.com.br/pedagogia/artigos/45866/adaptacoes-curriculares-naeducacao-inclusiva\#!1\#ixzz4ANISHVt6 Acesso em 01 de Maio de 2016, às 20h53min.

REILY, Lucia. O ensino de artes visuais na escola no contexto da inclusão. Artigo. Cad. Cedes, Campinas, vol. 30, n. 80, p. 84-102, jan.-abr. 2010. Disponível na biblioteca eletrônica SciELO. Disponível em: http://www.scielo.br/pdf/ccedes/v30n80/v30n80a07.pdf Acesso em 21 de Março de 2016, às 20h30min. 
SANTA CATARINA (Estado). Secretaria de Estado da Educação, Ciência e Tecnologia. Lei $n^{\circ}$ 17.143, de 15 de maio de 2017. Disponível em:

https://www.escavador.com/diarios/465180/DOESC/P/2017-05-17?page=2 Acesso em 29 de junho de 2017, às 16h00min.

SANTA CATARINA (Estado). Secretaria de Estado da Educação, Ciência e Tecnologia.

Fundação Catarinense de Educação Especial. Política de Educação Especial do Estado de Santa Catarina: proposta/Coordenador Sergio Otavio Bassetti. São José: FCEE, 2006. 52 p. Disponível em:

http://www.fcee.sc.gov.br/index.php?option=com_docman\&task=cat_view\&gid=45\&Itemid=91 Acesso em 29 de Abril de 2016, às 22h00min.

SANTA CATARINA (Estado). Secretaria de Estado da Educação. Fundação Catarinense de Educação Especial. Programa Pedagógico. São José, SC: FCEE, 2009. 20 p. Disponível em: http://www.fcee.sc.gov.br/index.php?option=com_docman\&task=doc_view\&gid=445 Acesso em 29 de Abril de 2016, às 23h00min.

SANTO AMARO DA IMPERATRIZ, Normativa $n^{\circ}$ 01, de 03 de Novembro de 2008. Dispõe sobre o procedimento de contratação do segundo professor para turmas que tenham matricula de alunos com deficiência. Disponível na Secretaria de Educação de Santo Amaro da Imperatriz

SCHAMBECK, Regina Finck. Formação de professores de Música para o contexto inclusivo: perspectivas de graduandos na preparação para atuar com alunos com deficiência. XXV

Congresso da Associação Nacional de Pesquisa e Pós-Graduação em Música - Vitória - 2015.

Disponível em:

file:///C:/Users/Jo\%C3\%A3o/Downloads/Forma\%C3\%A7\%C3\%A3o\%20de\%20professores\%2 0de\%20M\%C3\%BAsica\%20para\%20o\%20contexto\%20inclusivo..pdf Acesso em 19 de Maio de 2016, às 22h45min.

UNESCO. Declaração de Salamanca. Sobre Princípios, Políticas e Práticas na Área das Necessidades Educativas Especiais. Disponível em:

http://portal.mec.gov.br/seesp/arquivos/pdf/salamanca.pdf Acesso em 23 Maio. 2016, às $14 \mathrm{~h} 47 \mathrm{~min}$.

\footnotetext{
${ }^{\text {i }}$ Doutora em Educação. Professora do Programa de Pós Graduação em Música/PPGMUS e do Mestrado Profissional ProfArtes (CEART/UDESC), ambos da Universidade do Estado e Santa Catarina (UDESC).

${ }^{\text {ii } G r a d u a n d a}$ em Artes Visuais da Universidade do Estado de Santa Catarina (UDESC).

iii IBGE. Site: http://cidades.ibge.gov.br/xtras/perfil.php?codmun=421570

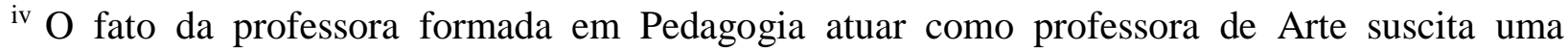
questão de análise, uma vez que todo o professor deveria ter formação na área de atuação, mas por questões de foco não vai ser discutida neste texto.
} 